(1)

CrossMark

\title{
On the valid publication of names of mycobacteria
}

To the Editor:

In their paper entitled "Same meat, different gravy: ignore the new names of mycobacteria", ToRTOLI et al. [1] called to ignore the recently proposed generic names Mycobacteroides, Mycolicibacter, Mycolicibacterium and Mycolicibacillus in which some species of Mycobacterium were reclassified [2], and to keep using the old names. The authors correctly stated that with the validation of the new names in the International Journal of Systematic and Evolutionary Microbiology (IJSEM) [3], the old names remain validly published and anyone is free to use them. By explaining this, they did a great service to the community of microbiologists and clinicians. Arguments similar to those presented by TorTOLI et al. [1] against the use of the newly proposed names were brought forward following a proposal to rename the clinically important Clostridium difficile as Clostridioides difficile [4]. A paper was published to clarify that both names are validly published and can be used [5].

Unfortunately, the editorial by TORTOLI et al. [1] contains many errors and misconceptions about the functioning of the International Code of Nomenclature of Prokaryotes (ICNP) [6] and the IJSEM that we wish to correct.

The bacterial taxonomy is ruled by the Code of nomenclature of prokaryotes (previously Bacteriological code): The correct name of the code is the International Code of Nomenclature of Prokaryotes Prokaryotic Code (2008 revision). The ICNP does not rule taxonomy. On the contrary, the Code states: "Nothing in this Code may be construed to restrict the freedom of taxonomic thought or action" (Principle 1(4)).

Actually the Code only provides valid names of bacteria: Based on the ICNP there are no valid names, only validly published names. The Code does not provide such names, but it contains the rules that regulate valid publication of names.

To be valid, a publication describing a new taxon needs to contain a protologue: There are no valid publications that describe new taxa; there only are validly published names of taxa. The word "protologue" is not found in the ICNP. It was proposed in 1999 [7], but was not adopted in the text of the Code. The requirements for the description of new taxa are found in Rule 27 and (for species) in Rule 30.

The publication in IJSEM automatically grants validity to a new name: Publication of a name in IJSEM can be considered to be validly published only if it conforms to the rules of the ICNP [8]. Thanks to its rigorous reviewing process, it seldom happens that problematic names of new taxa are published in the journal. When it does happen, a correction can be made in a Notification List. An example is the name Flavobacterium daemonensis which contravenes Rule $12 \mathrm{c}(1)$ and was corrected to Flavobacterium daemonense [9].

In contrast, in order for an organism name to be recognised as valid if published in other journals, the authors must request the new name to be included in a Validation list published, upon check of conformity, by IJSEM: According to Note 1 to Rule 27, requesting validation of names is not the privilege of the author of the effective publication; others may submit a new name or new combination for validation, provided it conforms to the Rules of this Code.

When a change of a validly published species or genus name is proposed, the new name, once validly published becomes a heterotypic synonym of the previous ones: "Heterotypic synonyms" means that

@ERSpublications

The message presented by Tortoli and co-workers in their paper "Same meat, different gravy: ignore the new names of mycobacteria" is correct, but the paper contains many errors and misconceptions about the functioning of the Prokaryotic Code and the IJSEM http://bit.ly/2YD9u6s

Cite this article as: Oren A, Trujillo ME. On the valid publication of names of mycobacteria. Eur Respir J 2019; 54: 1901483 [https://doi.org/10.1183/13993003.01483-2019]. 
different names have been associated with different types that in the opinion of the bacteriologist concerned belong to the same taxon (Rule 24a, Note 3). Of the new combinations discussed by TorTOLI et al. [1], the nomenclature types remain the same, so here we have homotypic synonyms, i.e. more than one name has been associated with the same type.

A validly published name is not ever withdrawn: This is incorrect: the Judicial Commission of the International Committee on Systematics of Prokaryotes (the ICSP) can place names on the list of rejected names (nomina rejicienda) (Rule 56a). One of the reasons to reject a name can be the case of a perilous name (nomen periculosum), a name whose application is likely to lead to accidents endangering health or life or both or of serious economic consequences. Therefore, the name Yersinia pseudotuberculosis subsp. pestis was rejected [10]. Scientists or clinicians who believe that the renaming Mycobacterium species may create nomina periculosa are free to submit a Request for an Opinion to the Judicial Commission and propose rejection of the names.

Overall, the updated nomenclature and its adoption in IJSEM ... does a disservice to microbiologists, clinicians and patients: Neither the IJSEM nor its Editorial Board are "adopting" the new nomenclature; the journal simply fulfils a service by including the names in a validation list as all requirements have been met, in accordance with the guidelines of ICSP and Rule 27 of the ICNP.

Aharon Oren $^{1}$ and Martha E. Trujillo ${ }^{2}$

${ }^{1}$ The Institute of Life Sciences, The Hebrew University of Jerusalem, Jerusalem, Israel. ${ }^{2}$ Departamento de Microbiología y Genética, Campus Miguel de Unamuno, Universidad de Salamanca, Salamanca, Spain.

Correspondence: Aharon Oren, Hebrew University of Jerusalem, Dept of Plant and Environmental Sciences, The Institute of Life Sciences, Edmond J. Safra Campus, Jerusalem, 9190401, Israel. E-mail: aharon.oren@mail.huji.ac.il

Received: 25 July 2019 | Accepted: 29 July 2019

Conflict of interest: None declared.

\section{References}

1 Tortoli E, Brown-Elliott BA, Chalmers JD, et al. Same meat, different gravy: ignore the new names of mycobacteria. Eur Respir J 2019; 54: 1900795.

2 Gupta RS, Lo B, Son J. Phylogenomics and comparative genomic studies robustly support division of the genus Mycobacterium into an emended genus Mycobacterium and four novel genera. Front Microbiol 2018; 9: 67.

3 Oren A, Garrity GM. List of new names and new combinations previously effectively, but not validly, published. Int J Syst Evol Microbiol 2018; 68: 1411-1417.

4 Lawson PA, Citron DM, Tyrrell KL, et al. Reclassification of Clostridium difficile as Clostridioides difficile (Tall and O’Toole 1935) Prévot 1938. Anaerobe 2016; 40: 95-99.

5 Oren A, Rupnik M. Clostridium difficile and Clostridioides difficile: Two validly published and correct names. Anaerobe 2018; 52: 125-126.

6 Parker CT, Tindall BJ, Garrity GM. International Code of Nomenclature of Prokaryotes. Int J Syst Evol Microbiol 2019; 69: S1-S111.

7 Tindall BJ. Proposals to update and make changes to the Bacteriological Code. Int J Syst Bacteriol 1999; 49: 1309-1312.

8 Tindall BJ, Kämpfer P, Euzéby JP, et al. Valid publication of names of prokaryotes according to the rules of nomenclature: past history and current practice. Int J Syst Evol Microbiol 2006; 56: 2715-2720.

9 Oren A, Garrity GM. Notification that new names of prokaryotes, new combinations, and new taxonomic opinions have appeared in volume 65, part 3, of the IJSEM. Int J Syst Evol Microbiol 2015; 65: 1701-1702.

10 Judicial Commission. Opinion 60. Rejection of the name Yersinia pseudotuberculosis subsp. pestis (van Loghem) Bercovier, et al. 1981 and conservation of the name Yersinia pestis (Lehmann and Neumann) van Loghem 1944 for the plague bacillus. Int J Syst Bacteriol 1985; 35: 540.

We are grateful to A. Oren and M.E. Trujillo for their precise clarifications. I admit that my knowledge about the complex rules governing the nomenclature of prokaryotes is very limited and dates back to no more than an year ago when, in reply to a manuscript of mine, a reviewer for the International Journal of Systematic and Evolutionary Microbiology invited me to read the papers of B.J. Tindall and co-workers [1, 2].

I am, at the same time, happy to read that A. Oren and M.E. Trujillo confirm the validity of what I consider the backbone of our editorial [3]: "the old names remain validly published and anyone is free to use them." It is indeed this freedom of choice that allowed us to receive the aversion of a large part of the clinician community against the splitting of mycobacteria among five genera and recommend to continue using the traditional nomenclature based on the genus Mycobacterium only. A recommendation, in line 
with taxonomic rules, that, in our opinion, allows to avoid confusion for the clinicians and harm for the patients.

@ERSpublications

The complex taxonomic rules do not affect the legitimacy of using the conventional nomenclature of mycobacteria based on the single genus Mycobacterium http://bit.ly/2L3mpKi

Cite this article as: Tortoli E. On the valid publication of names of mycobacteria. Eur Respir J 2019; 54: 1901623 [https://doi.org/10.1183/13993003.01623-2019].

\section{Enrico Tortoli}

Emerging Bacterial Pathogens Unit, IRCCS San Raffaele Scientific Institute, Milan, Italy.

Correspondence: Enrico Tortoli, Emerging Bacterial Pathogens Unit, IRCCS San Raffaele Scientific Institute, Via Olgettina 60, 20132, Milan, Italy. E-mail: tortoli.enrico@hsr.it

Received: 15 Aug 2019 | Accepted: 15 Aug 2019

Conflict of interest: None declared.

\section{References}

1 Tindall BJ. Misunderstanding the Bacteriological Code. Int J Syst Bacteriol 1999; 49: 1313-1316.

2 Tindall BJ, Kampfer P, Euzeby JP, et al. Valid publication of names of prokaryotes according to the rules of nomenclature: past history and current practice. Int J Syst Evol Microbiol 2006; 56: 2715-2720.

3 Tortoli E, Brown-Elliott BA, Chalmers JD, et al. Same meat, different gravy: ignore the new names of mycobacteria. Eur Respir J 2019; 54: 1900795. 